\title{
Adult education and child nutrition: the role of family and community
}

\author{
H Moestue, S Huttly
}

Nutrition and Public Health Intervention Research Unit, London School of Hygiene and Tropical Medicine, London, UK

Correspondence to:

H Moestue, London School of Hygiene and Tropical Medicine London, UK; helenmoestue@ gmail.com

The corresponding author is no longer at the London School of Hygiene and Tropical Medicine but can be reached at helenmoestue@gmail.com

Accepted 21 March 2007

\begin{abstract}
Background: It is well established that mothers' education has positive effects on child nutrition in developing countries. Less explored is the effect exerted by the education of other individuals - mothers' friends, neighbours and family.
\end{abstract}

Objectives: To examine independent effects of mothers', fathers' and grandmothers' education on child height-forage and weight-for-age z-score, and the role of community-level maternal literacy over and above parental education and other individual-level factors.

Methods: Cross-sectional data were analysed for 5692 children from Andhra Pradesh State in India and Vietnam sampled within "sites" (20 from each country) and then within "communities" (31 from Vietnam and 102 from India). Multilevel regression analysis was undertaken to account for confounders and geographical clustering of observations.

Results: Child nutrition is positively and independently associated with mothers', fathers' and grandmothers' education. The association with grandmothers' education was statistically significant in the India sample only and was stronger for boys: the adjusted mean difference in height-for-age z-scores between boys living with an educated grandmother and those not was 0.64 (95\% Cl 0.29 to $0.99, p<0.001)$. In the Vietnam sample, child nutrition was associated with the proportion of literate mothers in the community, adjusting for parental education and other confounders (height $0.81,95 \% \mathrm{Cl}$ 0.29 to $1.31, p=0.002$ ).

Conclusion: The results imply that an individual-level perspective may fail to capture the entire impact of education on child nutrition, and support a call for a widening of focus of nutrition policy and programmes from the mother-child pair towards the broader context of their family and community.

It is well established that mothers' education has a positive effect on child nutrition in developing countries. In school, girls can acquire skills that are later used to access modern health services and comprehend health messages. Less explored, however, is the effect exerted by the education of other individuals-mothers' friends, neighbours and family - who may influence child nutrition directly (though childcare) or indirectly (though modification of the effect of maternal education).

Despite recent improvements, approximately half of preschool children remain underweight in Asia, which is the highest level in the world; in India 62 million children are underweight and in Vietnam there are 5 million. ${ }^{12}$ In both countries there has been concern that economic advances have not been reflected in improvements in child nutrition..$^{3-5}$ Education is viewed as a key element in the overall strategy for reducing malnutrition in the developing world. This view is based on evidence spanning four decades for a positive effect of adult education on child health and nutrition in both developed and developing countries. ${ }^{6-10}$ The effect is particularly strong for female education. In India, education has been shown to explain the spatial clustering of malnutrition and death, ${ }^{11} 12$ and even low levels of education have been shown to increase child survival prospects and healthrelated behaviours. ${ }^{13}$

The positive effect of maternal education is, nevertheless, not universal. ${ }^{14}$ In Vietnam, a recent study using two nationally representative surveys found no significant effect of maternal education on child nutrition. ${ }^{45}$ This is perhaps because increased pressure on women to work outside the home has had negative consequences for childcare and breastfeeding practices, which may have outweighed any potential benefit of education.

It has been argued that children's greater "exposure time" to mothers explains why the effect of education is greater for mothers than fathers, as fathers tend to work outside the home. ${ }^{15}$ If, however, employment draws mothers away from childcare at home, the presence of other household members who are better educated than the mother may offer the potential for an improvement in the overall quality of childcare. This argument is supported by other studies drawing attention to the role played by older siblings and grandparents in childcare. ${ }^{12-16}$

The concept of "mass education" was first introduced by Caldwell ${ }^{6}$ in 1980 and developed by Cleland and Jejeebhoy, ${ }^{17}$ who used survey data from south Asia to demonstrate that in communities where the average level of education is high, the fertility of the women with little or no education is lower than would otherwise be expected. Kravdal ${ }^{18-20}$ claimed that an expansion of education would reduce mortality, not only because more women would enter an educational category associated with lower mortality, but also because all community members, including those who themselves remained uneducated, would benefit from the generally higher level of education in the community. These views are also shared by others. ${ }^{21-23}$

A review of the literature reveals that most studies of adult education and child nutrition have focused on parents only. Few have examined the effect of education among other household or community members, although recent research suggests that these "others" may play an important role in determining child nutrition. ${ }^{20-23}$ The objectives of this study are therefore to explore the 
effect of mothers', fathers' and grandmothers' education on child nutrition, and to estimate, using multilevel methods, the effect of community-level maternal literacy on child nutrition over and above parental education and other individual-level factors.

\section{METHODS}

\section{Study design}

This study uses cross-sectional data from the first round of the Young Lives study (in 2002) in Vietnam and Andhra Pradesh State in south India. Full details of the Young Lives study are available at www.younglives.org.uk. The data from the first round of the Young Lives study are available from the UK Public Archive, study no. SN5307 (www.esds.ac.uk). In each country approximately 3000 children were sampled from 20 sites: 2000 children aged 6 to 17.9 months at enrolment ("one-year olds") and 1000 children aged 7.5 to 8.5 years ("eight-year olds"). Sentinel sites, and the communities within the sites, were selected semipurposively. Households were selected using a method equivalent to random sampling. Detailed information on the study design and sampling methods has been published elsewhere. ${ }^{24-26}$ Although the data are not nationally representative, we will hereafter refer to the data being from "India" and "Vietnam".

\section{Main variables}

Anthropometric indices were used as indicators of child nutrition, following procedures recommended by the World Health Organisation. ${ }^{27-29}$ Children were classified as "stunted" (an indicator of chronic malnutrition) if they have height-forage z-scores below -2 SD and "underweight" (indicator of both chronic and acute malnutrition) if they have weight-for-age zscores below $-2 \mathrm{SD}^{28}{ }^{29}$ Education was measured by asking the respondent what level of formal schooling each household member had completed. The data were recoded into the four main categories: "none", "primary" (corresponding to ages 611 years), "secondary" (11-14/15 years) or "higher" (15 years or above). For grandmothers, all education categories were combined because only a small number of grandmothers had secondary or higher education. Community-level maternal literacy was measured as the proportion of mothers who were literate in the community, as estimated from the sample (data on paternal literacy was not available). Literacy was assessed by asking "Can you read and understand a letter or newspaper easily, with difficulty, or not at all, in any language?". Answers were coded "easily", "with difficulty" or "not at all". Women who answered "easily" were categorised as literate. The choice of a community-level literacy variable, rather than an education variable, is based on the hypothesis that literacy is the key outcome of education and that the "externality" of education is spread mainly through literacy mechanisms. ${ }^{30}$

\section{Statistical methods}

For descriptive analysis we used chi-squared tests, Student's $t$-tests and F-tests to assess the statistical significance of differences between proportions, two means or more than two means, respectively. Multivariable regression analysis was used to adjust simultaneously for multiple confounders. Confounders were selected on the basis of UNICEF's model for the determinants of malnutrition, which incorporates biological and socioeconomic causes at both micro and macro levels. ${ }^{31}$ Statistical interactions were assessed by entering a dummy interaction term into the model. Exact $p$ values are presented in the text and statistical significance was assumed at the $5 \%$ level, except for statistical interactions, which used the $10 \%$ level. A test for trend was undertaken by applying the likelihood ratio test between a model in which the categorical variable is specified as continuous and a model excluding this variable altogether. A three-level model is used to account for the hierarchical structure of the data, ${ }^{32}{ }^{33}$ in which level 1 refers to measurements of the individual child and the child's household, level 2 the community and level 3 the site. Data were analysed for 5692 children/households in which the mother was the main caregiver of the child; this included 1946 oneyear olds from Vietnam and 1899 from India, 963 eight-year olds from Vietnam and 884 from India, and excluding cases with missing values for any of the variables selected for use in the analysis $(\mathrm{N}=327)$.

Ethical clearance was obtained from participating research institutions in the United Kingdom and each Young Lives study country. Before interview, informed consent was obtained from participants.

\section{RESULTS}

The prevalence of stunting and underweight was $19 \%$ and $24 \%$ in Vietnam and $28 \%$ and $43 \%$ in India. The between-country differences correspond to what has been shown elsewhere, with Vietnamese children being better nourished on average than

Table 1 The level of schooling completed by mothers, fathers and grandmothers in India and Vietnam

\begin{tabular}{|c|c|c|}
\hline & India & Vietnam \\
\hline & $\mathbf{N}(\%)$ & N (\%) \\
\hline \multicolumn{3}{|l|}{ Mother } \\
\hline None & $1767(63.5)$ & $825(28.4)$ \\
\hline Primary & $278(10.0)$ & $1054(36.2)$ \\
\hline Secondary & $312(11.2)$ & $674(23.2)$ \\
\hline Higher & $426(15.3)$ & $356(12.2)$ \\
\hline \multicolumn{3}{|l|}{ Father } \\
\hline None & $1328(49.3)$ & $624(22.5)$ \\
\hline Primary & 314 (11.7) & 905 (32.6) \\
\hline Secondary & $321(11.9)$ & $751(27.0)$ \\
\hline Higher & $733(27.2)$ & 498 (17.9) \\
\hline \multicolumn{3}{|l|}{ Grandmother } \\
\hline None & $1009(88.2)$ & $343(65.6)$ \\
\hline Primary & $87(7.6)$ & $115(22.0)$ \\
\hline Secondary & $32(2.8)$ & 48 (9.2) \\
\hline Higher & $16(1.4)$ & $17(3.3)$ \\
\hline
\end{tabular}


Table 2 Regression output: the crude and adjusted association between maternal education and child height-for-age z-scores ( $\mathrm{N}=5692)$

\begin{tabular}{|c|c|c|c|c|c|c|c|c|c|c|c|c|}
\hline & \multicolumn{4}{|c|}{ Model A } & \multicolumn{4}{|c|}{ Model B } & \multicolumn{4}{|c|}{ Model C } \\
\hline & Coeff & SE & $\mathbf{p}_{1}$ & $\mathbf{p}_{2}$ & Coeff & SE & $\mathbf{p}_{1}$ & $\mathbf{p}_{2}$ & Coeff & SE & $\mathbf{p}_{1}$ & $\mathbf{p}_{2}$ \\
\hline Constant & -1.41 & 0.05 & 0.000 & & -1.34 & 0.12 & 0.000 & & -1.52 & 0.12 & 0.000 & \\
\hline \multicolumn{13}{|l|}{ Maternal education } \\
\hline Primary & 0.17 & 0.04 & 0.000 & & 0.11 & 0.04 & 0.013 & & 0.10 & 0.04 & 0.022 & \\
\hline Secondary & 0.22 & 0.05 & 0.000 & & 0.15 & 0.05 & 0.001 & & 0.15 & 0.05 & 0.002 & \\
\hline Higher & 0.48 & 0.05 & 0.000 & $<0.001$ & 0.38 & 0.05 & 0.000 & $<0.001$ & 10.35 & 0.05 & 0.000 & $<0.001$ \\
\hline \multicolumn{13}{|l|}{ Confounders } \\
\hline Housing quality score (household wealth) (0-1) & & & & 0.26 & 0.06 & 0.000 & & 0.28 & 0.06 & 0.000 & & \\
\hline Household land ownership (0, no; 1, yes) & & & & 0.04 & 0.04 & 0.326 & & 0.04 & 0.04 & 0.343 & & \\
\hline Adults in household (no.) & & & & 0.02 & 0.01 & 0.047 & & 0.01 & 0.01 & 0.261 & & \\
\hline Children in household (no.) & & & & -0.07 & 0.02 & 0.000 & & -0.06 & 0.02 & 0.000 & & \\
\hline Economic sectors household involved with (no.) & & & & 0.02 & 0.02 & 0.395 & & 0.02 & 0.02 & 0.281 & & \\
\hline Urbanity (0, rural; 1 , urban) & & & & 0.22 & 0.11 & 0.038 & & 0.21 & 0.11 & 0.050 & & \\
\hline
\end{tabular}

$\mathrm{p}_{1}, \mathrm{p}$ Value for categorical variable; $\mathrm{p}_{2}, \mathrm{p}$ value for linear variable.

Table 3 Regression output: the crude and adjusted association between maternal education and child weight-for-age z-scores ( $\mathrm{N}=5692$ )

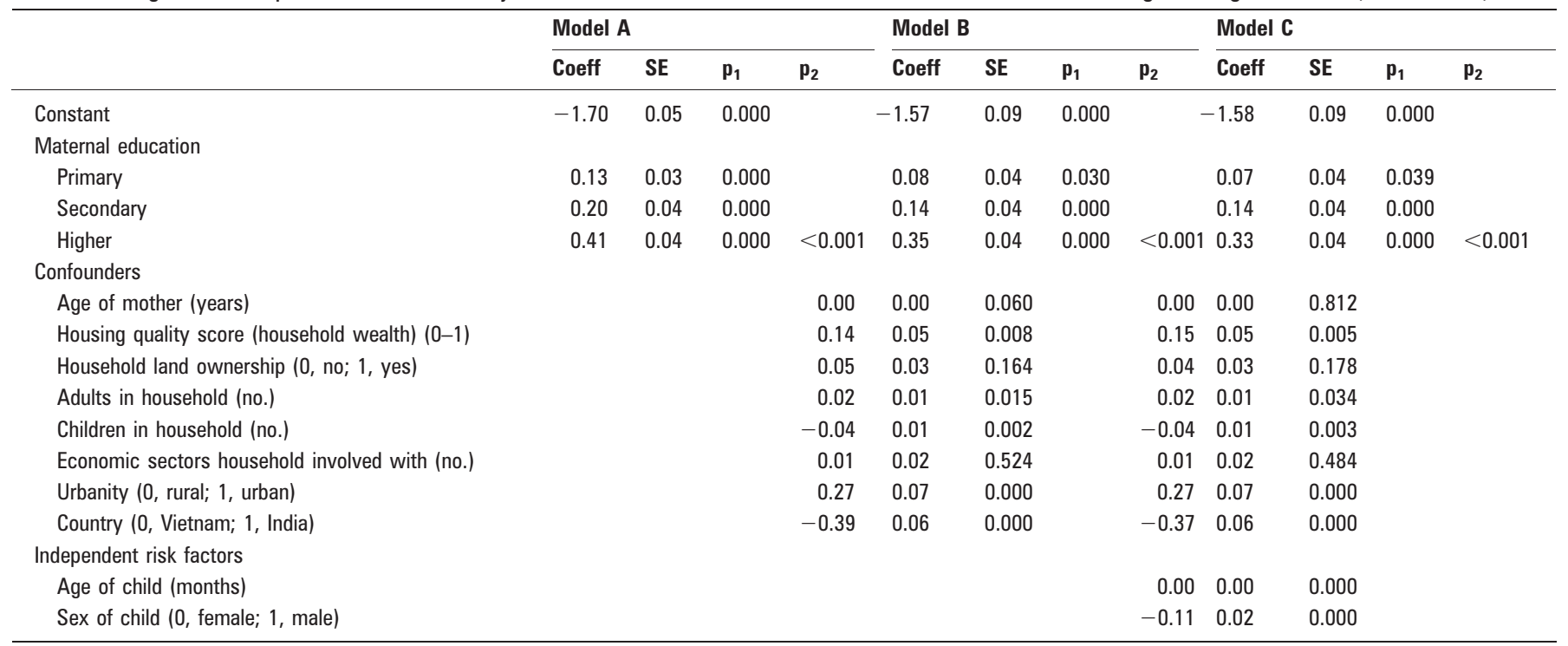

$p_{1}, p$ Value for categorical variable; $p_{2}, p$ value for linear variable.

Indian children. ${ }^{34}$ Table 1 shows the distribution of maternal, paternal and grandmother education in each country. It is apparent that adults have a higher level of schooling in Vietnam than in Andhra Pradesh $(p<0.001)$, which also corresponds to previous literature. ${ }^{35}$

\section{Objective 1: maternal education}

Tables 2 and 3 show, for height and weight-for-age, respectively, the crude effect of maternal education on child nutrition (model A), and the effect adjusting for confounders (model B) as well as independent risk factors (model C). The tables show that the crude effect diminishes somewhat after adjustment for potential confounders and risk factors, although it remains statistically significant and linear for both nutrition outcomes $(p<0.001)$. There was no difference in the education effect by country or child sex, but it was stronger in urban areas than rural (height $p=0.079$, weight $p<0.001$ ) and stronger among the relatively wealthy households than the poor (height $p=0.094$, weight $p=0.006$ ). Differences in the effect of education were, however, found between one and eight-year olds in terms of weight-for-age $(p<0.001)$, but not height-for-age $(p=0.849)$, with the effect on weight being greater for the one-year olds.

\section{Objective 2: paternal and grandmother education}

Table 4 shows that fathers' education is positively associated with nutrition, and that whereas the presence of a grandmother in the household is not associated with child nutrition, her education has a positive effect on height-for-age $(p=0.053)$ and weight-for-age $(p<0.001)$, adjusting for parental education and other confounders. Further analysis was undertaken to explore the role of grandmothers' education, as this is a relatively new area of interest within the literature. First, it was found that the effect was stronger in urban areas than rural (height $p=0.028$, weight $p=0.027$ ), as observed earlier for maternal education. 
Table 4 Regression output: the effect of grandmothers' presence and education on child height and weight-for-age z-scores in all households $(\mathrm{N}=5464)$

\begin{tabular}{|c|c|c|c|c|c|c|c|c|}
\hline & \multicolumn{4}{|c|}{ Height-for-age } & \multicolumn{4}{|c|}{ Weight-for-age } \\
\hline & Coeff & SE & $\mathbf{p}_{1}$ & $\mathbf{p}_{2}$ & Coeff & SE & $\mathbf{p}_{1}$ & $\mathbf{p}_{2}$ \\
\hline Constant & -1.494 & 0.123 & 0.000 & & -1.568 & 0.097 & 0.000 & \\
\hline \multicolumn{9}{|l|}{ Maternal education } \\
\hline Primary & 0.060 & 0.044 & 0.172 & & 0.045 & 0.038 & 0.232 & \\
\hline Secondary & 0.055 & 0.051 & 0.282 & & 0.071 & 0.043 & 0.097 & \\
\hline Higher & 0.224 & 0.060 & 0.000 & 0.001 & 0.230 & 0.051 & 0.000 & $<0.001$ \\
\hline \multicolumn{9}{|l|}{ Paternal education } \\
\hline Primary & 0.021 & 0.044 & 0.639 & & 0.016 & 0.038 & 0.669 & \\
\hline Secondary & 0.130 & 0.048 & 0.007 & & 0.064 & 0.041 & 0.119 & \\
\hline Higher & 0.213 & 0.051 & 0.000 & $<0.001$ & 0.162 & 0.043 & 0.000 & $<0.001$ \\
\hline \multicolumn{9}{|l|}{ Grandmother status } \\
\hline Present uneducated & -0.056 & 0.044 & 0.197 & & -0.031 & 0.037 & 0.408 & \\
\hline Present educated & 0.131 & 0.070 & 0.063 & 0.461 & 0.194 & 0.060 & 0.001 & 0.043 \\
\hline \multicolumn{9}{|l|}{ Confounders } \\
\hline Age of mother (years) & 0.242 & 0.065 & 0.000 & & 0.115 & 0.055 & 0.036 & \\
\hline Housing quality score (household wealth) $(0-1)$ & 0.036 & 0.040 & 0.374 & & 0.057 & 0.034 & 0.095 & \\
\hline Household land ownership (0, no; 1, yes) & 0.008 & 0.011 & 0.488 & & 0.010 & 0.009 & 0.304 & \\
\hline Adults in household (no.) & -0.055 & 0.017 & 0.001 & & -0.041 & 0.014 & 0.005 & \\
\hline Children in household (no.) & 0.017 & 0.021 & 0.410 & & 0.010 & 0.018 & 0.574 & \\
\hline Economic sectors household involved with (no.) & 0.188 & 0.108 & 0.082 & & 0.261 & 0.072 & 0.000 & \\
\hline Urbanity $(0$, rural; 1 , urban) & -0.097 & 0.094 & 0.301 & & -0.376 & 0.061 & 0.000 & \\
\hline Country (0, Vietnam; 1, India) & 0.242 & 0.065 & 0.000 & & 0.115 & 0.055 & 0.036 & \\
\hline \multicolumn{9}{|l|}{ Independent risk factors } \\
\hline Age of child (months) & -0.004 & 0.000 & 0.000 & & -0.001 & 0.000 & 0.001 & \\
\hline Sex of child $(0$, female; 1 , male $)$ & -0.138 & 0.029 & 0.000 & & -0.105 & 0.025 & 0.000 & \\
\hline
\end{tabular}

$p_{1}, p$ Value for categorical variable; $p_{2}, p$ value for linear variable.

Second, it was found that the effect was only evident in India and was stronger for boys than girls. In India the mean difference between boys having an educated grandmother in the household and boys who did not was 0.64 height-for-age zscores (95\% confidence interval (CI) 0.29 to $0.99, p<0.001$ ) and 0.52 weight-for-age $z$-scores ( $95 \%$ CI 0.25 to $0.78, \mathrm{p}<0.001$ ). The difference was smaller for Indian girls $(0.07,95 \% \mathrm{CI}-0.24$ to $0.36, p=0.671$ for height-for-age, and $0.29,95 \%$ CI 0.07 to $0.52, p=0.010$ for weight-for-age) and was statistically nonsignificant for both sexes in Vietnam.

\section{Objective 3: community-level education}

Tables 5 and 6 show, for height and weight-for-age, respectively, the crude results (model A), the results adjusted for potential confounders and risk factors but excluding parental education (model B), and the results adjusted for all confounders and risk factors, including parental education (model C). Adjustment for non-education confounders and independent risk factors diminishes the effect estimates for community-level maternal literacy, although the effect remains statistically significant for both height-for-age $(p=0.002)$ and weight-forage $(p=0.031)$. Once parental education has also been accounted for, however, the positive effect is reduced; the statistical significance of the effect disappears for child weightfor-age $(p=0.496)$ but remains borderline for height-for-age $(p=0.073)$. Once stratified by country, the results reveal that the effect is only significant in Vietnam (Vietnam 0.81, 95\% CI 0.29 to $1.31, p=0.002$; India $0.12,95 \% \mathrm{CI}-0.31$ to 0.55 , $p=0.577)$. The lack of an effect in India may be explained by the particular definition of a "community", which in India was "a small village or a cluster of hamlets" and the small sample size of households within some of the communities sampled.

\section{DISCUSSION}

The study has demonstrated a positive association between child nutrition-both stunting and underweight-and the education of adults living within the child's household and community. Particularly interesting, given the lack of previous evidence, is the positive association shown between child nutrition and grandmothers' education in India and community-level maternal literacy in Vietnam.

The positive association with grandmothers' education in India is plausible given the overwhelming evidence of health benefits of female education, and given what we know about grandmothers' responsibilities in childcare. ${ }^{36}$ It supports previous studies that have highlighted the role of grandmothers in determining health and fertility behaviour, whether "positively" or "negatively", and which call for a greater participation of grandmothers in behavioural-change interventions. ${ }^{36-38}$

The positive association between child nutrition and community-level maternal literacy in Vietnam, over and above parental education and other individual-level confounders and risk factors, suggests that children may benefit from living in literate communities. Again, this is highly plausible. Despite the economic transition of the past 20 years, Vietnam's social structure is still largely influenced by the socialist planned economy. The literacy of other members of a "commune" can therefore realistically affect childcare through the sharing of knowledge and imitation of behaviour. Educated people often create demand for services and infrastructure and tend to have more political clout than less educated populations. ${ }^{23}$

This research adds to the overwhelming evidence for a positive effect of adult education on child nutrition. Educationeffects were similar for both height and weight-for-age z-scores, suggesting they operate over the medium to longer term. The study also shows-in contrast to some other studies in the 
Table 5 Regression output: the crude and adjusted association between community-level maternal literacy and height-for-age z-scores ( $\mathrm{N}=5474)$

\begin{tabular}{|c|c|c|c|c|c|c|c|c|c|}
\hline & \multicolumn{3}{|c|}{ Model A } & \multicolumn{3}{|c|}{ Model B } & \multicolumn{3}{|c|}{ Model C } \\
\hline & Coeff & SE & $\mathbf{p}$ & Coeff & SE & $\mathbf{p}$ & Coeff & SE & $\mathbf{p}$ \\
\hline Constant & -1.597 & 0.080 & 0.000 & -1.830 & 0.163 & 0.000 & -1.699 & 0.166 & 0.000 \\
\hline Community-level maternal literacy $(0-1)$ & 0.624 & 0.120 & 0.000 & 0.493 & 0.160 & 0.002 & 0.295 & 0.165 & 0.073 \\
\hline Independent risk factors & & & & -0.005 & 0.000 & 0.000 & -0.004 & 0.000 & 0.000 \\
\hline Age of child (months) & & & & -0.145 & 0.029 & 0.000 & -0.140 & 0.029 & 0.000 \\
\hline \multicolumn{10}{|l|}{ Sex of child $(0$, female; 1 , male $)$} \\
\hline \multicolumn{10}{|l|}{ Confounders } \\
\hline Age of mother (years) & & & & 0.008 & 0.003 & 0.004 & 0.008 & 0.003 & 0.006 \\
\hline Housing quality score (household wealth) (0-1) & & & & 0.358 & 0.064 & 0.000 & 0.241 & 0.065 & 0.000 \\
\hline Household land ownership (0, no; 1, yes) & & & & 0.057 & 0.040 & 0.158 & 0.034 & 0.040 & 0.389 \\
\hline Adults in household (no.) & & & & 0.008 & 0.009 & 0.372 & 0.006 & 0.009 & 0.545 \\
\hline Children in household (no.) & & & & -0.065 & 0.017 & 0.000 & -0.055 & 0.017 & 0.001 \\
\hline Economic sectors household involved with (no.) & & & & 0.027 & 0.021 & 0.195 & 0.018 & 0.021 & 0.398 \\
\hline Urbanity $(0$, rural; 1 , urban $)$ & & & & 0.163 & 0.114 & 0.152 & 0.115 & 0.113 & 0.312 \\
\hline Country $(0$, Vietnam; 1 , India) & & & & 0.127 & 0.117 & 0.278 & 0.028 & 0.118 & 0.810 \\
\hline \multicolumn{10}{|l|}{ Maternal education } \\
\hline Primary & & & & & & & 0.054 & 0.045 & 0.223 \\
\hline Secondary & & & & & & & 0.048 & 0.051 & 0.345 \\
\hline Higher & & & & & & & 0.221 & 0.060 & 0.000 \\
\hline \multicolumn{10}{|l|}{ Paternal education } \\
\hline Primary & & & & & & & 0.018 & 0.044 & 0.677 \\
\hline Secondary & & & & & & & 0.125 & 0.048 & 0.010 \\
\hline Higher & & & & & & & 0.212 & 0.051 & 0.000 \\
\hline
\end{tabular}

Table 6 Regression output: the crude and adjusted association between community-level maternal literacy and weight-for-age z-scores ( $\mathrm{N}=5474$ )

\begin{tabular}{|c|c|c|c|c|c|c|c|c|c|}
\hline & \multicolumn{3}{|c|}{ Model A } & \multicolumn{3}{|c|}{ Model B } & \multicolumn{3}{|c|}{ Model C } \\
\hline & Coeff & SE & $\mathbf{p}$ & Coeff & SE & $\mathbf{p}$ & Coeff & SE & $\mathbf{p}$ \\
\hline Constant & -1.944 & 0.061 & 0.000 & -1.753 & 0.128 & 0.000 & -1.623 & 0.127 & 0.000 \\
\hline \multicolumn{10}{|l|}{ Independent risk factors } \\
\hline Age of child (months) & & & & -0.001 & 0.000 & 0.000 & -0.001 & 0.000 & 0.001 \\
\hline Sex of child $(0$, female; 1 , male) & & & & -0.111 & 0.025 & 0.000 & -0.107 & 0.025 & 0.000 \\
\hline Housing quality score (household wealth) (0-1) & & & & 0.227 & 0.054 & 0.000 & 0.120 & 0.055 & 0.028 \\
\hline Household land ownership (0, no; 1 , yes) & & & & 0.077 & 0.034 & 0.024 & 0.056 & 0.034 & 0.096 \\
\hline Adults in household (no.) & & & & 0.015 & 0.008 & 0.052 & 0.013 & 0.008 & 0.101 \\
\hline Children in household (no.) & & & & -0.049 & 0.014 & 0.001 & -0.041 & 0.014 & 0.005 \\
\hline Economic sectors household involved with (no.) & & & & 0.017 & 0.018 & 0.339 & 0.010 & 0.018 & 0.586 \\
\hline Urbanity $(0$, rural; 1 , urban) & & & & 0.292 & 0.082 & 0.000 & 0.246 & 0.078 & 0.002 \\
\hline \multicolumn{10}{|l|}{ Maternal education } \\
\hline Higher & & & & & & & 0.238 & 0.051 & 0.000 \\
\hline \multicolumn{10}{|l|}{ Paternal education } \\
\hline Primary & & & & & & & 0.017 & 0.038 & 0.660 \\
\hline Secondary & & & & & & & 0.062 & 0.041 & 0.133 \\
\hline Higher & & & & & & & 0.166 & 0.043 & 0.000 \\
\hline
\end{tabular}

past - that fathers' education is associated with child nutrition, and that this association was as strong as mothers' education. ${ }^{38}$ It is plausible that fathers, often heading the households, make decisions and behave in ways that directly or indirectly affect childcare.

The difference in findings between India and Vietnam may be explained by differences in the cultural significance placed on the extended family or commune/community. For example, grandmothers in India and communes in Vietnam are known to exert strong influences on childcare, so it is not unexpected that this study finds an effect of their education. Between-country differences may also be the result of methodological factors, such as the size and structure of the two datasets. For example, the absence in India (in contrast with Vietnam) of an effect of community-level maternal literacy may be explained by the small size of the communities selected-this argument is supported by findings from a recent nationwide study in India showing a clear positive effect of community-level education on 


\section{What this paper adds}

- It is well established that mothers' education has a positive effect on child nutrition in developing countries. Less explored, however, is the effect exerted by the education of other individuals - mothers' friends, neighbours and family — who may influence child nutrition directly (though childcare) or indirectly (though modification of the effect of maternal education).

- This study shows that children's nutrition is associated with the education of many adult household and community members. Particularly interesting, given the lack of previous evidence, is the finding that child nutrition in one sample (India) is positively associated with grandmothers' education, and that in the other sample (Vietnam), child nutrition is positively associated with community-level maternal literacy. The findings imply that an individual-level perspective may fail to capture the entire impact of education on child nutrition, and support a call for a widening of focus of nutrition policy and programmes from the mother-child pair towards the broader context of their family and community.

child mortality. ${ }^{20}$ Similarly, the lack of an effect of grandmothers' education in Vietnam (in contrast with India) may be explained, partly at least, by the small number of grandmothers included in the sample. Both methodological and cultural factors may thus lie behind the between-country differences observed. Furthermore, one should bear in mind, when interpreting the results, that the data were cross-sectional, meaning that causality cannot be proved and that further longitudinal research would be necessary to corroborate the findings.

Despite these weaknesses, this small study has succeeded in linking a number of key issues of interest among educationalists, economists and nutritionists, and highlighting their synergies. Within the disciplines of education and economics, the issue of education "externalities" is currently much debated, with increasingly sophisticated methods being developed to capture the social "knock-on" effects from investments in education. ${ }^{30} 40$ The findings presented here demonstrate that externalities of education are observed both within and between households, that the externalities can be measured through child anthropometry, and that an individual-level perspective may fail to capture the entire impact of education on child nutrition.

There are two implications for nutrition policy emerging from this research. First it supports existing efforts to universalise basic education and adult literacy programmes, as education is positively associated with child nutrition. The second implication is more novel: policies currently aimed at improving child nutrition may benefit from recognising and including key actors other than the mother. It is plausible that the common approach of targeting women of reproductive age for health or nutrition interventions may overlook "influential others" in childcare and therefore miss useful avenues of influence. This study shows that mothers play a role in determining child nutrition, as well as fathers, grandmothers and the community at large. This is a timely finding as there is an increasing realisation within the field of nutrition that changing mothers' behaviour through targeted health education is difficult without simultaneously tackling underlying societal issues and intra-household power relations, which are known to

\section{Policy implications}

There are two major policy implications from this research. First it supports existing efforts to universalise basic education and adult literacy programmes, as education is positively associated with child nutrition. The second implication is more novel: policies currently aimed at improving child nutrition may benefit from recognising key actors other than the mother. The common approach of targeting women of reproductive age for health and nutrition interventions may overlook "influential others" in the family or community. Now that a growing number of women in India and Vietnam are taking up employment outside the household, the role of other carers such as grandmothers and siblings is likely to become increasingly important in determining child nutrition. Therefore the findings support a call to widen the focus of nutrition policy and programmes from the mother-child pair towards the broader context of their family and community.

influence mothers' decision-making and actions. ${ }^{37} 4142$ Moreover, as Asian countries undergo globalisation, and increasing numbers of mothers take up employment outside the home, other carers such as grandmothers and siblings are likely to play an increasingly important role in determining child nutrition and health. We therefore support a call to widen the focus of nutrition policy and programmes from the motherchild pair towards the broader context of their family and community, including mothers' social networks as well as locally influential individuals such as teachers and community leaders. ${ }^{43}$

Further research is needed to corroborate the findings and interpretations presented here, in particular to improve our understanding of the mechanisms that underlie the relationship between child nutrition and adult education, including education measured at the community level. In addition, programmatic research is needed to explore practical ways in which to involve influential household and community members including mother-in-laws, teachers and local leaders, in nutritional interventions to increase programme effectiveness.

Acknowledgements: Access to the Young Lives data via the UK data archive is gratefully acknowledged.

Funding: The research studentship of HM was funded by the Medical Research Council.

Competing interests: None.

\section{REFERENCES}

1. de Onis $\mathbf{M}$, Frongillo EA, Blossner M. Is malnutrition declining? An analysis of changes in levels of child malnutrition since 1980. Bull WHO 2000;78:1222-33.

2. Mason J, Hunt J, Parker D, et al. Investing in child nutrition in Asia. Asian Dev Rev 1999;17:1-32.

3. Claeson M, Bos ER, Mawji $T$, et al. Reducing child mortality in India in the new millennium. Bull WHO 2000;78:1192-9.

4. Thang NM, Popkin B. Child malnutrition in Vietnam and its transition in an era of economic growth. J Hum Nutr Diet 2003;16:233-44.

5. Glewwe $\mathbf{P}$, Koch S, Nguyen BL. Child nutrition, economic growth and the provision of health care services in Vietnam in the 1990s. Policy research working paper series 2776. Washington, DC: World Bank, 2002.

6. Caldwell J. Mass education as a determinant of the timing of fertility decline. Popul Dev Rev 1980;6:225-55.

7. Cleland JG, Van Ginneken JK. Maternal education and child survival in developing countries: the search for pathways of influence. Soc Sci Med 1988;27:1357-68.

8. Cochrane SH, O'Hara D, Leslie J. The effects of education on health. Washington, DC: World Bank, 1980.

9. Frost MB, Forste R, Haas DW. Maternal education and child nutritional status in Bolivia: finding the links. Soc Sci Med 2005;60:395-407.

10. Bicego GT, Boerma JT. Maternal education and child survival: a comparative study of survey data from 17 countries. Soc Sci Med 1993;36:1207-27. 
11. Griffiths $\mathbf{P}$, Matthews $Z$, Hinde A. Gender, family, and the nutritional status of children in three culturally contrasting states of India. Soc Sci Med 2002;55:775-90.

12. Das Gupta M. Death clustering, mothers' education and the determinants of child mortality in rural Punjab, India. Popul Stud (Camb) 1990;44:489-505.

13. Basu AM, Stephenson R. Low levels of maternal education and the proximate determinants of childhood mortality: a little learning is not a dangerous thing. Soc Sci Med 2005;60:2011-23.

14. White $\mathbf{H}$, Masset E. Child poverty in Vietnam: using adult equivalence scales to estimate income-poverty in Vietnam. Young Lives 2002.www.younglives.org.uk (accessed 1 June 2005).

15. Bishai D. Quality time: how parents' schooling affects child health through its interaction with childcare time in Bangladesh. Health Econ 1996;5:383-407.

16. Van Esterik P. Care, caregiving, and caregivers. Food Nutr Bull 1995;16:378-88.

17. Cleland J, Jejeebhoy SJ. Maternal schooling and fertility: evidence from census and surveys. In: Jeffrey R and AM Basu, eds. Girls' schooling, women's autonomy and fertility change in South Asia. New Dehli: Sage Publications, 1996.

18. Kravdal 0. A search for aggregate-level effects of education on fertility, using data from Zimbabwe. http://www.demographic_research.org/Volumes/Vol3/3 laccessed 1 June 2005).

19. Kravdal 0. Education and fertility in sub-Saharan Africa: individual and community effects. Demography 2002;39:233-50.

20. Kravdal 0. Child mortality in India: the community-level effect of education. Popul Stud (Camb) 2004:58:177-92.

21. Moursund A, Kravdal 0 . Individual and community effects of women's education and autonomy on contraceptive use in India. Popul Stud (Camb) 2003:57:285-301.

22. McNay K, Arokiasamy P, Cassen R. Why are uneducated women in India using contraception? A multilevel analysis. Popul Stud (Camb) 2003;57:21-40.

23. Alderman H, Hentschel J, Sabates R. With the help of one's neighbors: externalities in the production of nutrition in Peru. Soc Sci Med 2003;56:2019-31.

24. Wilson I, Huttly SR. Young Lives: a case study of sample design for longitudinal research. Working paper no. 10. Young Lives 2004.www.younglives.org.uk (accessed 1 June 2005).

25. Galab S, Gopinath MR, Antony P, et al. Young Lives preliminary country report: Andhra Pradesh India. Young Lives 2003.www.younglives.org.uk laccessed 1 June 2005).
26. Tuan T, Lan PT, Harpham T, et al. Young Lives preliminary country report: Vietnam. Young Lives 2004.www.younglives.org.uk (accessed 1 June 2005).

27. Hamill PV, Drizd TA, Johnson CL, et al. Physical growth: National Center for Health Statistics percentiles. Am J Clin Nutr 1979:32:607-29.

28. World Health Organization. Use and interpretation of anthropometric indicators of nutritional status. Bull WHO 1986;64:929-41.

29. World Health Organization. Physical status: the use and interpretation of anthropometry. Geneva: World Health Organization, 1995.

30. Basu K, Narayan A, Ravallion M. Is literacy shared within households? Theory and evidence for Bangladesh. Labour Econ 2001;8:649-65.

31. UNICEF. The state of the world's children. New York: UNICEF, 1998

32. Goldstein H. Multilevel modelling of survey data. The Statistician 1991;40:235-44.

33. Rabash J, Browne W, Goldstein H, et al. A user's guide to MLwiN. London: Institute of Education, 2000.

34. de Onis M, Monteiro C, Akre J, et al. The worldwide magnitude of protein-energy malnutrition: an overview from the WHO Global Database on Child Growth. Bull WHO 1993;71:703-12.

35. UNESCO. Comparing education statistics across the world. Montreal, Canada: UNESCO Institute for Statistics, Global Education Digest, 2004.

36. Sharma M, Kanani S. Grandmothers' influence on child care. Indian J Pediat 2006;73:295-8.

37. Aubel J, Toure I, Diagne M. Senegalese grandmothers promote improved maternal and child nutrition practices: the guardians of tradition are not adverse to change. Soc Sci Med 2004;59:945-59.

38. Hobcraft JN, McDonald JW, Rutstein SO. Socio-economic factors in infant and child mortality: a cross-national comparison. Popul Stud (Camb) 1984;38:193-223.

39. Sear R, Mace R, McGregor IA. Maternal grandmothers improve nutritional status and survival of children in rural Gambia. Proc Biol Sci 2000;267:1641-7.

40. Gibson J. Literacy and intrahousehold externalities. World Dev 2001;29:155-66.

41. Save the Children UK. Thin on the ground: questioning the evidence behind World Bank-funded community nutrition projects in Bangladesh, Ethiopia and Uganda. London: Save the Children, 2003.

42. Good B. Medicine, rationality, and experience: an anthropological perspective. Cambridge; New York: Cambridge University Press, 1994.

43. Moestue H, Huttly SR, Sarella L, et al. 'The bigger the better' - mothers' social networks and child nutrition in Andhra Pradesh. Public Health Nutr 2007:10:1274-82.

\section{BNF for Children 2006, second annual edition}

In a single resource:

- guidance on drug management of common childhood conditions

- hands-on information on prescribing, monitoring and administering medicines to children

- comprehensive guidance covering neonates to adolescents

For more information please go to bnfc.org. 